\title{
Microdeterminação do arsênico ${ }^{(*)}$
}

\section{GUIDO RANRANI}

\author{
Assistente da 2.a Cadetra - Quimica Agricola
}

\section{INDICE}

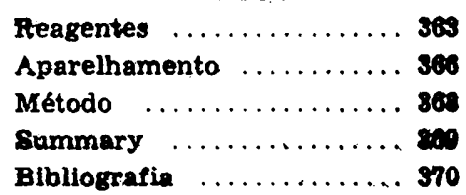

(*) 0 autor consigna qqui, seus agradeeimentos ts sugestőes do Prof. Dz José de Mello Moraes, sob cuja orientaçăo geral êste trabalho fọ tei to. Agradece também a valiosa colaboraçio do seu auxiliar de labo ratório Axmando Porta. 
Os métodos para microdeterminaçăo do Arsênico (12) podem ser enquadrados nos seguintes:

1 - O método de MARSH-BERSELIUS (4,5 e 6) baseado na formação de um espélho de arsênico, proveniente da decomposição da arsenamina pelo calor.

2 - O método do brometo (2), constante da distilação do arsênico sob a forma de cloreto arsenioso e titulaçăo posterior com bromato de potássio.

3 - Os métodos lodométricos (11), baseados na obtenção da arsenamina, sendo esta recebida em uma soluçáo de cloreto mercúrico, o ácido arsenioso resultante dosado por titulação com iodo; ou o Arsênico é precipitado pelo ácido hipofosção com iodo; ou o Arsénico é precipitado pelo ácido hipofosforoso (21), dissolvido em excesso (quantidade medida) da solução de Koppeschaar (brometo e bromato potássicos), sendo o hologeno em excesso determinado por iodometria, empregando-se para tal um "buffer", o fosfato bissódico.

4 - Os métodos colorimétricos $(12,13,14,15,16,17,18,19$ e 20), basezdos na formaça do "complexo azul de molibdenio",

5 - Os métodos néfelométricos (20), fundamentados na medida da turvaçăo, ocasionada pelo pentóxido de arsenico, em presença de ácido clorídrico, soluçáo de cocaína e molibdato de potássio.

6 - O método de GUTZEIT $(1,2,7,8$ e 24): formação da arsenamina e reação da mesma com papeis em fitas ou em discos, impregnados com cloreto ou brometo mercúrico. 0 método de ROSE (9) : a arsenamina atua sobbre nitrato de prata; TRUFFERT (10): emprega papeis fotográficos revestidos com citrato de prata; THORPE (23) : obteve a arsenamina năo a partir de zinco e acido, mas pelo hidrogênio catódico; HOW (7) : substitui os papeis sensibilizados, por tubos capllares contendo cloreto mercúrico depositado por evaporação de uma solução alcoolica dêsse sal.

Dentre as modificações propostas, algumas conservam relativa simplicidade, enquanto outras, implicam em instalaçóes custosas e aparelhamento especial, requisitos êsses nem sempre dentro das possibilidades dos laboratórios, principalmente para aquêles onde determinaçőes dessa natureza são feitas poucas vezes.

Foram aqui levadas a efeito inúmeras tentativas, mantidas sëmṕre dentro dos limites de material dum laboratorio simples; procurándo tanto quanto possivel, allar à simplicidade a precisăo em determinaçōes de micro e ultra-micro quantidades. Dessas acomodações e ligeiras modificaçóes de métodos, 
tendo por base fundamental o método oficial recomendado pela "Assoc. Off. Agr. Chem." resultou uma nova técnica, apresentando as caracteristicas seguintes :

a) O emprêgo de blocos cilíndricos de zinco, segundo $H$. I. GOLDSTONE (1). Para maior precisăo, os cilindros foram torneados e cortados no próprio torno. Empregaram-se 2 cillindros de zinco em cada determinaçăo, oferecendo uma área total de $530,66 \mathrm{~mm} 2$, o que dispensa a fonte suplementar de gases recomendada por $\mathbf{C}$. E. LACHELE (3).

b) Adatação de três séries de tubos, ao mesmo conjunto, de tal modo a condicionar a área de papel sensibillzado, à quantidade de arsentico presente na substancia em análise. Tal prática conduz, pela reduçáo da área de papel atingida pela arsenamina, à obtençăo de discos mais intensamente coloridos, principalmente para trabalhos com ultra-micro quantldades.

c) Montagem dos discas obtidos, entre duas laminas de vidro, as quais, quando convenientemente preparadas, contribuem năo só para maior durabilidade dos padrōes e problema, como também facilitam as comparaçoes.

d) Distençăo dos limites da quantidade de Arsenico, determinável pelos métodas que lhe servem de base, pois fornece resultados comparávels para $0.00001 \mathrm{mgr}$. de As2O3, ou o que equivale a dizer para 0.000007575 mgrs. de As.

\section{REAGENTES}

\section{1 - Solução de Cloreto Estanoso :}

Dissolver 40 grs. de SnCl2,2H2O isento de arsenico, em ácido clorídrico e completar o volume para $100 \mathrm{cc}$. com o ácido. A solução é mantida em frascos de 50 cc. providos de conta-gotas com rolha esmerilhada.

\section{2 - Solução de Iodeto de Potássio :}

Dissolver 15 grs. de KI em água e diluir para $100 \mathrm{cc}$. Conservar em frascos coloridos.

\section{3 - Solução de Acetato de Chumbo a 10\%:}


Dissolver 10 grs. de acetato de chumbo em água, adicionar algumas gotas de CH3COOH até clarear a soluçăo e diluir para 100 cc. Consercar em frascos providos de conta-gotas com rolha esmerilhada.

\section{Papel de Acetato de Chumbo :}

Mergulhar na solução de acetato de chumbo papeis de filtro Whatman n.o 41. Secar em posiçăo horizontal sobre bastonetes de vidro. Cortar, com auxilio de um vasador metálico, em discos de $27 \mathrm{mms}$. de diâmetro.

\section{5 - Solução de Brometo Mercúrico :}

Dissolver 5 grs. de HgBr2 em álcool a 95\%. Filtrar e, com - mesmo álcool diluir para 100 cc. Conservar em frasco colorido.

\section{6 - Discos de papel sensibilizado :}

Selecionar de acórdo com o peso e textura, papeis de filtro S \& $\mathbf{S}$ n. ${ }^{\circ} 58$ os quais, depois de cortados em fitas de mais ou menos $20 \mathrm{mms}$. de largura, são mergulhados na solução alcoólica de HgBr2. Em vez de preparar papeis sensibilizados cada vez que se pratica uma determinação, (1), um maço constituido por 30-50 fitas de mais ou menos $10 \mathrm{cms}$. de comprimento é suspenso por uma extremidade na solução alcoolica de HgBr2 por um bastonete de vidro prêso à rolha do frasco. O frasco, preferivelmente de vidro escuro é conservado em ausencia de luz. Os papeis são assim conservados inalterados por alguns méses (1). Dessa maneira tem-se à mão sempre, papeis recémpreparados.

\section{7 - Hidróxido de Sódio a $20 \%$ :}

Dissolver 20 grs. de hidróxido de sódio em água distilada e dilulr para 100 cc. A solução é conservada em vidro Pyrex.

$$
8 \text { - Zinco }
$$

H. I. GOLDSTONE (1) ređuz o êrro no emprégo do método de GUTZEIT, usando blocos cilindricos de zinco os quais expбem uma superfície constante ao ataque do ácido. Para moldar as barra: cilindricas empregou tubos Pyrex de 15x125 mm., cu:dadosamente escolhidos. Os tubos são suspensas em pasição vertical e aquecidos à chama do bico de gás, enquanto quanti- 
dade suficiente do zinco é fundida em vaso Pyrex. A massa fundida é trasvazada para o tubo; o zinco é delxado esfriar gradualmente, incidindo a chama na parte superior do tubo de tal modo que essa parte do zinco se mantenha em estado liquido por mais tempo. Esta precauçăo contribui para a obtençáo de cilindros untformes.

Por falta de quantidade suficiente de tubos uniformes em diametro interno e pela dificuldade encontrada em se eliminarem as bolhas de ar na superfícle da barra de zinco, procedeu-se a obtenção das mesmas, sendo para isso empregados tubos de mais ou menos $15 \mathrm{~m}$. de diámetro. $O$ zinco é deixado esfriar; o cilindro é retirado quebrando-se o tubo. Os cilindros foram entăo torneados, e no próprio torno, cortadas em pedaços de $15 \mathrm{~mm}$. de comprimento por $13 \mathrm{~mm}$. de diametro.

Preparou-se (1) uma pasta constituida por carbonato de magnésio e goma arábica. As superficies planas dos cillindros de zinco sáo protegldas com essa pasta; pelas extremidades, uma após outra, os cilindros săo depois mergulhados em uma mistura de tres partes de parafina e uma parte de cera animal, fundidas, repetindo-se a operaçáo de modo a obter uma camada protetora de mais ou menos 1,5 mm. sobre a superficie cilíndrica do zinco. As superficies planas săo entăo raspadas com auxilio de um canivete e lavadas com água, afim de remover a pasta e a mistura de cera e parafina al solidificadas.

Assim preparado, o zinco é ativado como recomenda o método oficial (2), isto é, tratado durante 15 minutos com HC1 $(1+3)$ ao qual se adicionam 2 cc. da soluçâo de $\mathbf{s}$ C12. em seguida guardado sob $\mathrm{H} 2 \mathrm{O}$ contendo 1 gota de $\mathrm{HCl}$. A parafina exposta, por dissoluçăo do zinco, é retirada antes de se efetuar alguma determinação.

\section{9 - Solução de Iodeto de Cádmio :}

Dissolver 20 rs. de CdI2 em água e diluir para $100 \mathrm{cc}$

\section{0 - Solução padrão de Arsênico :}

\section{a) Para mili e microgramos}

Dissolver 1 gr. de As2O3 em 25 cc. de NaOH a 20\%. Saturar com $\mathrm{CO} 2$ e diluir para 1.000 cc., 1 cc. desta soluçøo contém 1 mgr. de As2O3. Diluir 50 cc. desta soluçăo para 1.000 cc. e desta última 20 cc. sáo diluldos para 1.000 cc.; 1 cc. desta ultima soluçáo contém $0,001 \mathrm{mgr}$. de As203. (soluçăo A). 


\section{b) Para fraçōes. de microgramos.}

1) 10 cc. da solução A são diluidos para 100 cc.; 1 cc. dessa soluçáo contém $0,0001 \mathrm{mgr}$. de AsO3 ou 0,0000757 mgrs. de As.

2) 10 cc. da soluçáo $A$ săo diluidos para 1.000 cc.; 1 cc. dessa solução sontém $0,00001 \mathrm{mgr}$. de As2O3 ou 0,000007575 mgrs. de As.

Estas soluções diluidas tem que ser sempre de preparação recente; a concentraçăo diminui com rapidez (22) em relação ao tempo.

\section{APARELHAMENTO}

O frasco redutor (fig. 1A), um balăo de Jena, fundo chato, de 250 cc., tendo previamente marcado o volume de 50 cc. Para eliminaçåo de H2S, sulfetos, etc. empregou-se um pequeno tubo, (tubo lavador) de $23 \mathrm{~mm}$. de diametro, afilado numa das extremidades; presta-se para tal, uma alonga da trompa de Kitasato. Carrega-se o tubo lavador com u'a mecha de algodšo de vidro, comprimida por um disco de papel de filtro. Uma vez carregado com uma camada de $10 \mathrm{mms}$. de algodăo de vidro, umedecido com 6 a 8 gotas da soluçăo de acetato de chumbo, adatam-se mais dols discos de papel de acetato de chumbo prèviamente sêcos, estes distando um do outro mais ou menos $10 \mathrm{mms}$. Tal cuidado contribul para melhor retençăo da umidade no tubo lavador. (Fig. 1-B.C.).

Os tubas de $20 \mathrm{~mm}$. de diâmetro, para montagem dos diafragmas de papel sensibilizado, como recomenda C. E. LACFEIE (3), são aqui substituidos por 3 conjuntos com dímetro interno respetivamente de $3 \mathrm{~mm}$., $5 \mathrm{~mm}$ e $9 \mathrm{~mm}$., empregados de acordo com a quantidade de arsenico presente na amostra. As duas partes de cada conjunto (fig. 1 D) adatam-se por suas extremidades planas.

As séries de tubos são empregadas como segue:

a) diámetro $3 \mathrm{~mm}$., para quantidades compreendidas entre 0,00001 a 0,00070 mgrs. de AsO3. (Fig. $1 \mathrm{E}$ ).

b) diâmetro $5 \mathrm{~mm}$., para quantidades compreendidas entre 0,0006 a 0,0014 mgrs. de As2O3. (Fig. 1 F).

c) diâmetro $9 \mathrm{~mm}$., para quantidades compreendidas entre 0,001 a 0,020 mgrs. de As2O3. (Flg. $1 \mathrm{G}$ ).

Os discos de papel sensibilizado são presos entre as superfícies planas dos dois tubos, em cada conjunto, por meio de um tubo de borracha de $2 \mathrm{cms}$. de comprimento. (Fig. $1 \mathrm{D}$ ). 


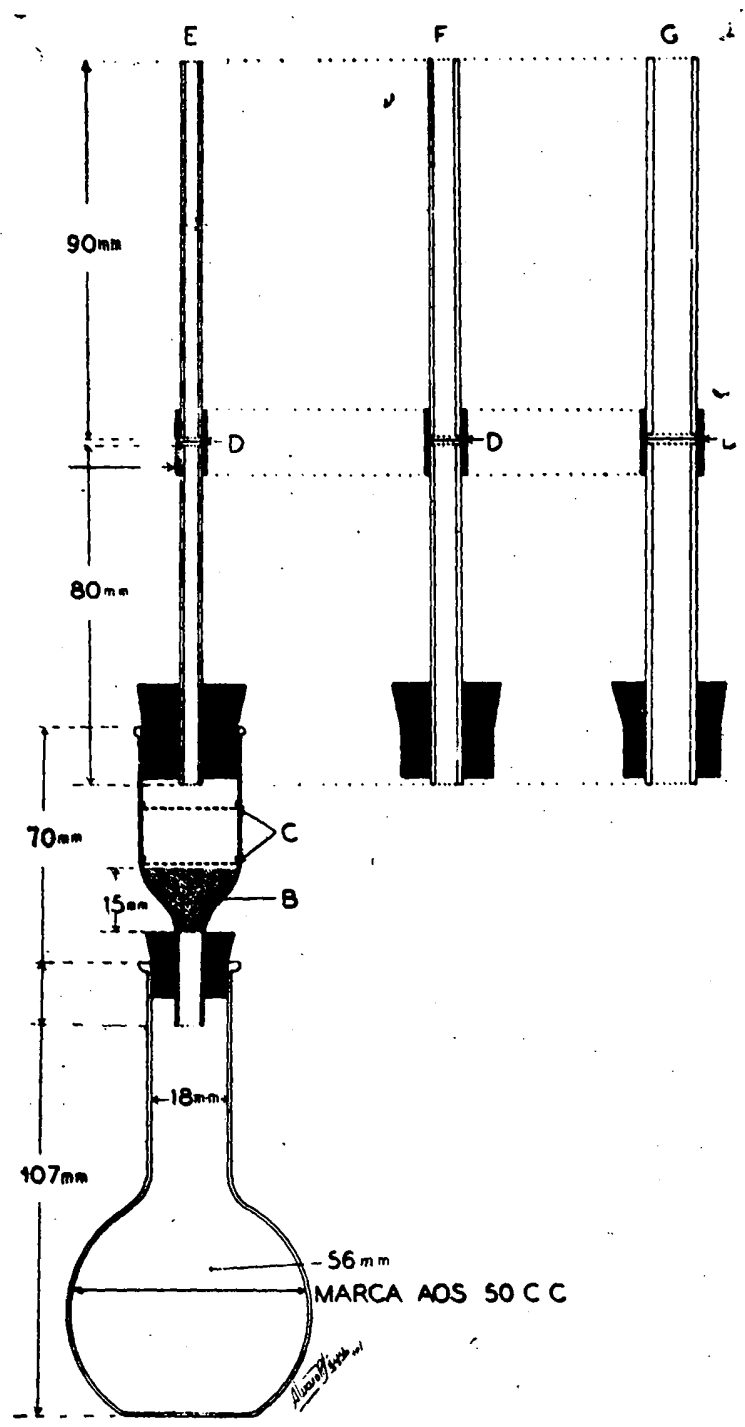

Fig. I - A - frasco redutor (Jena 250 cc.). Tubo lavador (B - algodáo de vidro). Tubo lavador - (C - papeis de acetato de chumbo). D conexão de borracha para adaptação dos discos de papel de brometo mercúrico. $\mathbf{E}$ - tubos de vidro, diâmetro interno $3 \mathrm{~mm}$. F - tubos de vidro, diametro interno $5 \mathrm{~mm}$. G - tubos de vidro, diametro interno $9 \mathrm{~mm}$ 


\section{METODO}

Săo tomadas porções alíquotas da soluçăo padrăo, diretamente no frasco redutor, provido de marca aos $50 \mathrm{cc}$., empregando-se para isso sempre a mesma bureta. Adicionar $5 \mathrm{cc}$. de HC1 conc. (2) escriar, 5 cc. da soluçăo de KI, e 5 gotas da soluçáo de sncl2. Completar com água o volume até a marca, agitar, e deixar em repouso 30 minutos.

- Preparar o restante do aparelho, adatando ao tubo terminal (parte que fica ligada ao frasco lavador), provido de conexăo de borracha (dobrada sobre si mesma, de modo a expor a superficie plana do vidro), o disco de papel sensibilizado, prèviamente obtido com auxilio de um vasador de diametro interno conveniente, e seco entre dois vidros planos; ajustar o outro tuba e ligar as duas partes deslizando a porçáo dobrada do tubo de borracha.

Colocar dois cllindros de zinco no gargalo do frasco redutor, inclinando-se o frasco de modo a se adatar o conjunto representado pelo tubo lavador e tubos terminais, antes que os cilindros de zinco entrem em contato com a soluçăo. $O$ conjunto é mantido à temperatura de $25^{\circ} \mathrm{C}$., mergulhando o frasco redutor até $3 \mathrm{cms}$., em água a essa temperatura. Torna-se necessários inclinar levemente o conjunto, de vez em quando, de modo a permitir o destacamento da finissima rede formada nas superficies planas dos blocos de zinco, à medida que a produção de gás progride. Os blocos de zinco devem manter-se com as superfícies planas livres, isto é, apolados sobre a superfícle cillíndrica; em tal posiçáo a massa pegajasa, escura rede formada nas superficies do metal em contato com a solução - destaca-se pelo próprio desprendimento gasoso, indo aflorar à superfície do liquido. Estas condiçరes são mantidas até o final da reação, o que se consegue depois de $\mathbf{9 0}$ minutos.

Quando a reaçăo se completou, as discos de papel săo removidos e mergulhados na soluçăo de CdI2, afim de fixar a coloraçăo mais fortemente (3), protegendo-a melhor contra a ação da luz e umidade.

Os discos são banhados na soluçăo de CdI2 até que todo o lodeto mercúrico vermelho, imediatamente formado, se dissolva. Com o uso, a soluçăo de CdI2 torna-se amarela, devido a formaçáo de complexas - lodeto-cadmio-mercúricas; nessas condiçães é necessário substitufila por outra.

O excesso de reagentes é removido agora com água, se- 
guindo-se a esta, uma lavagem em álcool a 95\%. Os discos săo a seguir recebldos sobre papel de filtro para secagem ao ar, em ausencia de luz.

Os discos "padróes" obtidos como acima foi exposto estáo prontos para o confronto com os discos do "problema", advindos da aplicação do mesmo processo sobre as substancias em análise.

Depois de inumeras tentativas para a bóa conservação dos padrōes, chegou-se à conclusăo de que u'a montagem dos discos de papel entre duas laminas de vidro oferece mais facilidade às comparaçóes. A técnica empregada é a que segue :

Tendo por molde uma lamina de vidro (de microscópio) $75 \times 25 \mathrm{~mm}$., cortar folhas de papel cartolina branco. Nestas pequenas folhas de papel fazer uma série de furos em sentido longitudinal guardando a distancia de $5 \mathrm{mms}$. do bordo livre, (Fig. 2 e 2A). Tal disposição dos furos permite que na própria matriz de papel se façam anotaçбes, que correspondam as amostras, ou aos padróes. As duas laminas e a matriz de papel já convenientemente preparadas vão para a estufa à temperatura de $70^{\circ} \mathrm{C}$, durante 15 minutos; sobre uma das lâminas de vidro, receber os resultados finais (escala colorida) nos furos do papel cartolina; cobrir com a outra lamina e parafinar a montagem assim conseguida, mergulhando-se um após outro os bordos das laminas em parafina fundida. Consegue-se deste modo a montagem dos resultados obtidos e, desde que sejam guardados em ausencia de luz, conservam-se por multo tempo inalterados.

\section{SUMMARY}

Studying the application of those methods of microanalysis which avoid costly instalations and atempting to combine high precision with low cost, the author recomends a new method consisting of the following :

a) exposure of a surface of $530.66 \mathrm{~mm}^{2}$ of $\mathrm{Zn}$ to the action of the acid.

b) Instalation of 3 series of HgBr2 paper in test tubes with an internal diameter of respectively 3,6 and $9 \mathrm{~mm}$.

c - mouting between two slides, covering the margins (with parafin etc.) with parafin in order to conserve the results of the determination without change due to the action of light or molsture.

d) the results can be compared at a level of $0.00001 \mathrm{mgr}$. A2O3 or $0.000007575 \mathrm{mgr}$. As. 


\section{BIBLIOGRAFIA}

( 1) H. I. GOLDSTONE - Ind. Eng. Chem. Anal. 18-797 (1946).

(2) Assoc. Official Agr. Chem., "Official an Tentative Methods of Analysis" 5 th ed. (1940).

( 3) C. E. LACHELE - Ind. Eng. Chem. Anal 6-255 (1934).

( 4)CURTMAN, “Qualitative Chemical Analysis", N. Y. Mac. Millan Co., 1931.

(5) LUNGE and KEANE "Tecnical Methods of Chemical Analysis", N. Y. D. Van Nostrand Co., 1942.

( 6) MONIER - WIILIAMS, Analyst, 48-112 (1923).

( 7) HOW, Ind. Eng. Chem., Anal. Ed. 10-226 (1938).

( 8) JACOBS, "Chemical Analysis of Foods and Foods Produuts. 1938.

(9) FRESENIUS and COHN, "Quantitative Chemical Analysis". 1912.

(10) TRUFFERT, Ann. Fals., 31-73 (1938).

(11) CASSIL and WICHMANN. J. Assoc. Offic. Agr. Chem., 22436 (1939).

(12) JACOBS and NAGLER - Ind. Eng. Chem. Anal. Ed. 14442 (1942).

(13) MAECHLING and FLINN. J. Lab. Clin. Med. 15-779 (1930).

(14) YOUNGBOURG and FARBER - idem - 17-363 (1932).

(15) ZINZADZE, Ind. Eng. Chem. Anal| Ed., 7,227-230 (1935).

(16) MORRIS and GALVERY, idem - 9-447 (1937).

(17) CHANEY and MEGNUSON - idem - 12-691 (1940).

(18) KUTTNER and COHEN - J. Biol. Chem. 75-517 (1927).

(19) SCHRICKER and DAWSON - J. Assoc. Offic. Agr. Chem., 22-167 (1939).

(20) KLEIMANN and PANGRITZ, Biochem. Z., 185-14 (1927).

(21) SLOVITER, MC NABB and WAGNER - Ind. Eng. Chem. Anal. Ed. 14-516 (1942).

(22) F. P. TRADWELL - Trat. Quim. Anal. - Tomo II - 181.

(23) T. E. THORPE - Proc. Chem. Soc. 19-183 (1903).

(24) J. HEFTI - Tesis doctoral, Zürich, 1907. 


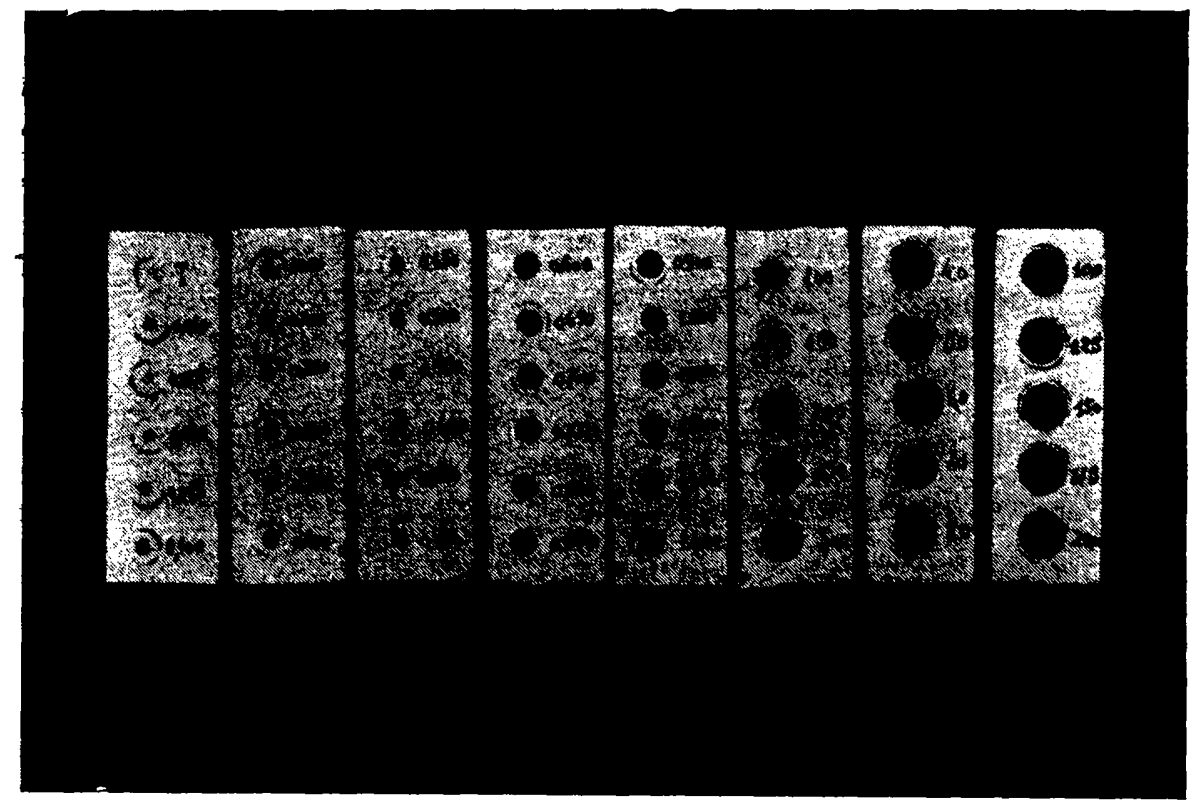

Fig. 2 - Escala colorida (montagem dos padrōes) em microgramos. De 0,010 a $0,700 \mathrm{u}$ grs. - tubos de $3 \mathrm{~mm}$. De 0,600 a $1,400 \mathrm{u}$ grs. - tubos de $5 \mathrm{~mm}$. De 1,000 a 20,000 u grs. - tubos de $9 \mathrm{~mm}$. 


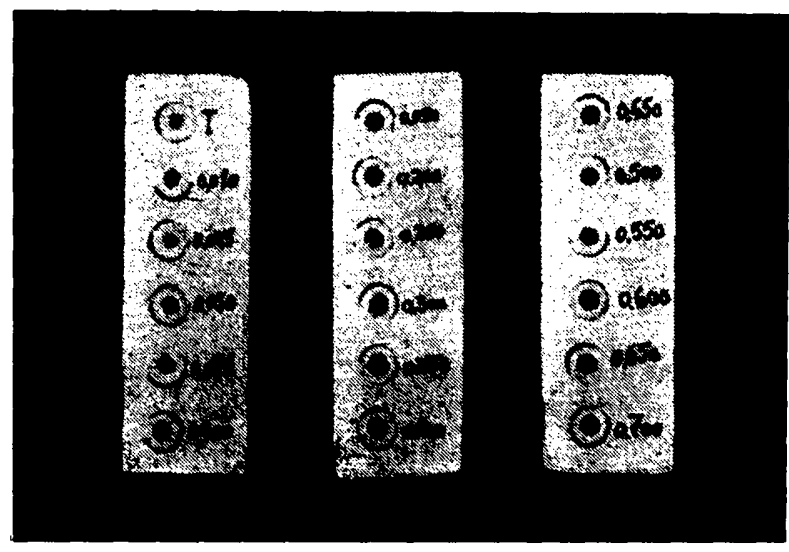

Tubos de $3 \mathrm{~mm}$.

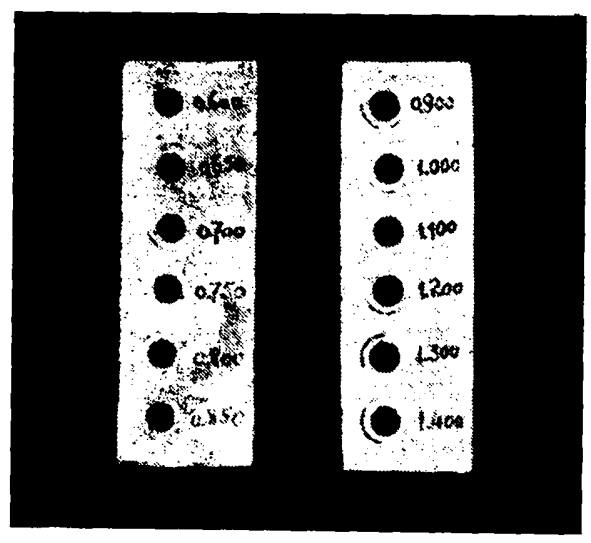

Tubos de $5 \mathrm{~mm}$.

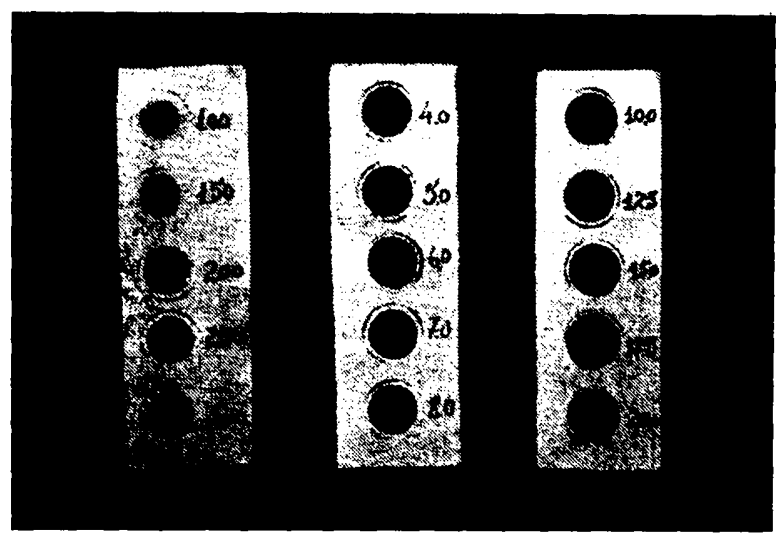

Tubos de $9 \mathrm{~mm}$.

Fig. 2 A - Escala colorida (montagem dos padrōes). 